Article

\title{
Cytotoxic Action of Artemisinin and Scopoletin on Planktonic Forms and on Biofilms of Candida Species
}

\author{
Sourav Das ${ }^{1,2}$ (), Lilla Czuni ${ }^{3,4}$, Viktória Báló ${ }^{3}$, Gábor Papp ${ }^{3,4}$, Zoltán Gazdag ${ }^{3,4}$, Nóra Papp ${ }^{5}$ \\ and Tamás Kőszegi ${ }^{1,2, * \mathbb{D}}$ \\ 1 Department of Laboratory Medicine, University of Pécs, Medical School, 7624 Pécs, Ifjúság u. 13., Hungary; \\ pharma.souravdas@gmail.com \\ 2 János Szentágothai Research Center, University of Pécs, 7624 Pécs, Ifjúság u. 20., Hungary \\ 3 Department of General and Environmental Microbiology, Institute of Biology, University of Pécs, 7624 Pécs, \\ Ifjúság u. 6., Hungary; czuni.lilla@gmail.com (L.C.); balo.viktoria@gmail.com (V.B.); \\ pappgab@gamma.ttk.pte.hu (G.P.); gazdag@gamma.ttk.pte.hu (Z.G.) \\ 4 Microbial Biotechnology Research Group, János Szentágothai Research Center, University of Pécs, 7624 Pécs, \\ Ifjúság u. 20., Hungary \\ 5 Department of Pharmacognosy, University of Pécs, Faculty of Pharmacy, 7624 Pécs, Rókus u. 2, Hungary; \\ nora4595@gamma.ttk.pte.hu \\ * Correspondence: tamas.koszegi@aok.pte.hu or koszegi.tamas@pte.hu; Tel.: +36-30-4917719
}

Received: 18 December 2019; Accepted: 20 January 2020; Published: 22 January 2020

check for updates

\begin{abstract}
We investigated the antifungal activities of purified plant metabolites artemisinin (Ar) and scopoletin (Sc) including inhibition, effects on metabolic activities, viability, and oxidative stress on planktonic forms and on preformed biofilms of seven Candida species. The characteristic minimum inhibitory concentration $\left(\mathrm{MIC}_{90}\right.$ ) of $\mathrm{Ar}$ and Sc against Candida species ranged from $21.83-142.1 \mu \mathrm{g} / \mathrm{mL}$ and $67.22-119.4 \mu \mathrm{g} / \mathrm{mL}$, respectively. Drug concentrations causing $\approx 10 \% \mathrm{CFU}$ decrease within 60 min of treatments were also determined (minimum effective concentration, $\mathrm{MEC}_{10}$ ) using 100-fold higher CFUs than in the case of $\mathrm{MIC}_{90}$ studies. Cytotoxic effects on planktonic and on mature biofilms of Candida species at $\mathrm{MEC}_{10}$ concentrations were further evaluated with fluorescent live/dead discrimination techniques. Candida glabrata, Candida guilliermondii, and Candida parapsilosis were the species most sensitive to Ar and Sc. Ar and Sc were also found to promote the accumulation of intracellular reactive oxygen species (ROS) by increasing oxidative stress at their respective $\mathrm{MEC}_{10}$ concentrations against the tested planktonic Candida species. Ar and Sc possess dose-dependent antifungal action but the underlying mechanism type (fungistatic and fungicidal) is not clear yet. Our data suggest that Ar and Sc found in herbal plants might have potential usage in the fight against Candida biofilms.
\end{abstract}

Keywords: Candida species; artemisinin; scopoletin; oxidative stress; mature biofilm; antifungal effect

\section{Introduction}

Fungal biofilms play an important role in numerous infections. They are composed of structural microbial communities adhering to different surfaces and being enveloped by the exopolymeric matrix [1]. Development of biofilms hinders the action of the defense system of the host and increases the resistance to standard antifungal agents [2]. Candida species like Candida albicans (C. albicans), Candida dubliniensis (C. dubliniensis), Candida tropicalis (C. tropicalis), Candida krusei (C. krusei), Candida glabrata (C. glabrata), Candida guilliermondii (C. gulliermondii), and Candida parapsilosis (C. parapsilosis) are fungal species of major medical importance. Candida species, members of human microflora, are diploid polymorphic yeasts [3] that can be found in the human gastrointestinal, respiratory, and inside the genitourinary tracts; therefore, C. albicans is found in vaginal, mucosal, and deep tissue 
infections $[2,4,5]$. In certain individuals with immune-compromised status, the Candida species might induce consequent infection. Also, Candida species can rapidly adapt to the host's micro-environmental circumstances caused by $\mathrm{pH}$ and nutritional changes in the gastrointestinal tract [1]. Environmental imbalance because of nutritional change or $\mathrm{pH}$ shifting facilitates the abnormal growth of Candida species which results in candidiasis [6]. Candida species attack the gut epithelium barriers to reach the bloodstream via micro-fold cells (M cells) that are found in the gut-associated lymphoid tissue (GALT) of Peyer's patches in the small intestine promoting intestinal infections [4]. Esophageal candidiasis is one of the major and common infections in people living with HIV/AIDS [1]. Symptoms of candidiasis in the mouth, throat, and esophagus generally include swallowing problems and pain [7,8]. Because of the increasing incidence of candidiasis and the difficulties in its treatment because of the limited options in the use of antifungal drugs with species-specific efficacy [9], there is an ultimate need for at least prevention of fungal infections.

Artemisinin (Ar), belonging to a family of sesquiterpene lactones originally derived from Artemisia annua L. is well-known for its anti-malarial actions by forming free radicals through cleavage of intra-parasitic iron-endoperoxide groups and by alkylation of specific malarial proteins mediating eradication of Plasmodium species [10]. Protection against cancers and inflammation by artemisinin has also been documented [11]. Ar has been reported to possess anti-infective activity against viruses (Human cytomegalovirus) and fungi (Cryptococcus neoformans) [12].

Scopoletin (Sc, 6-methoxy-7-hydroxycoumarin) is a phenolic compound isolated from several plants including A. annua L. [13]. Sc possesses anti-tumor and anti-angiogenesis properties by initiating cell cycle arrest and facilitating apoptosis in human prostate tumor cells and leukemia cell lines [14,15]. Although anti-fungal effects including anti-Candida activity of Ar and Sc were already studied, yet no detailed data are found in the literature on Candida species' viability and biofilm formation treated with $\mathrm{Ar}$ and $\mathrm{Sc}$ at their minimum effective concentration $\left(\mathrm{MEC}_{10}\right)$. Moreover, there are no experimental results obtained by using the double-stain rapid fluorescent assay for live/dead cellular discrimination along with metabolic activity determination for Ar- and Sc-exposed Candida species.

Because of the diverse biological activities including reactive oxygen species (ROS) generation $[13,14,16,17]$, we hypothesized that both Ar and Sc having a wide range of biological actions might exert antimicrobial activity as well. Therefore, the aim of our present study is to contribute to the knowledge of the hypothesized anti-microbial and anti-biofilm activity of Ar and Sc regarding their effects on C. albicans and on non-albicans species. The effect of Ar and Sc on cellular viability, metabolic activity (enzymatic reducing ability) and oxidative stress balance of the Candida species was evaluated by SYBR green I-propidium iodide double staining method, resazurin assay, dihydroethidium (DHE) and dihydrorhodamine 123 (DHR 123) fluorescence assays, respectively. The biomass and metabolic activity of the living cells in the mature biofilms were assessed by colorimetric and double fluorescence staining techniques.

\section{Results}

\subsection{Antifungal Activities (MIC ${ }_{90}$ ) of Artemisinin and Scopoletin}

Average $\mathrm{MIC}_{90}$ data obtained after $48 \mathrm{~h}$ of treatment with Ar and Sc for seven Candida spp. are presented in Figure 1. Ar MIC 90 ranged from 21.83 to $142.1 \mu \mathrm{g} / \mathrm{mL}$, while Sc MIC 90 was between 83.43 and $119 \mu \mathrm{g} / \mathrm{mL}$ taking all the tested Candida species. Ar MIC 90 values were significantly lower than those of Sc in the case of C. dubliniensis, C. krusei, and C. parapsilosis $(p<0.01)$. C. glabrata and C. tropicalis was more susceptible to Sc (67.22 and $119 \mu \mathrm{g} / \mathrm{mL}$, respectively). However, in general Ar expressed higher fungicidal activity than Sc at concentrations in the range of 27 to $80 \%$, less than was seen for Sc. 

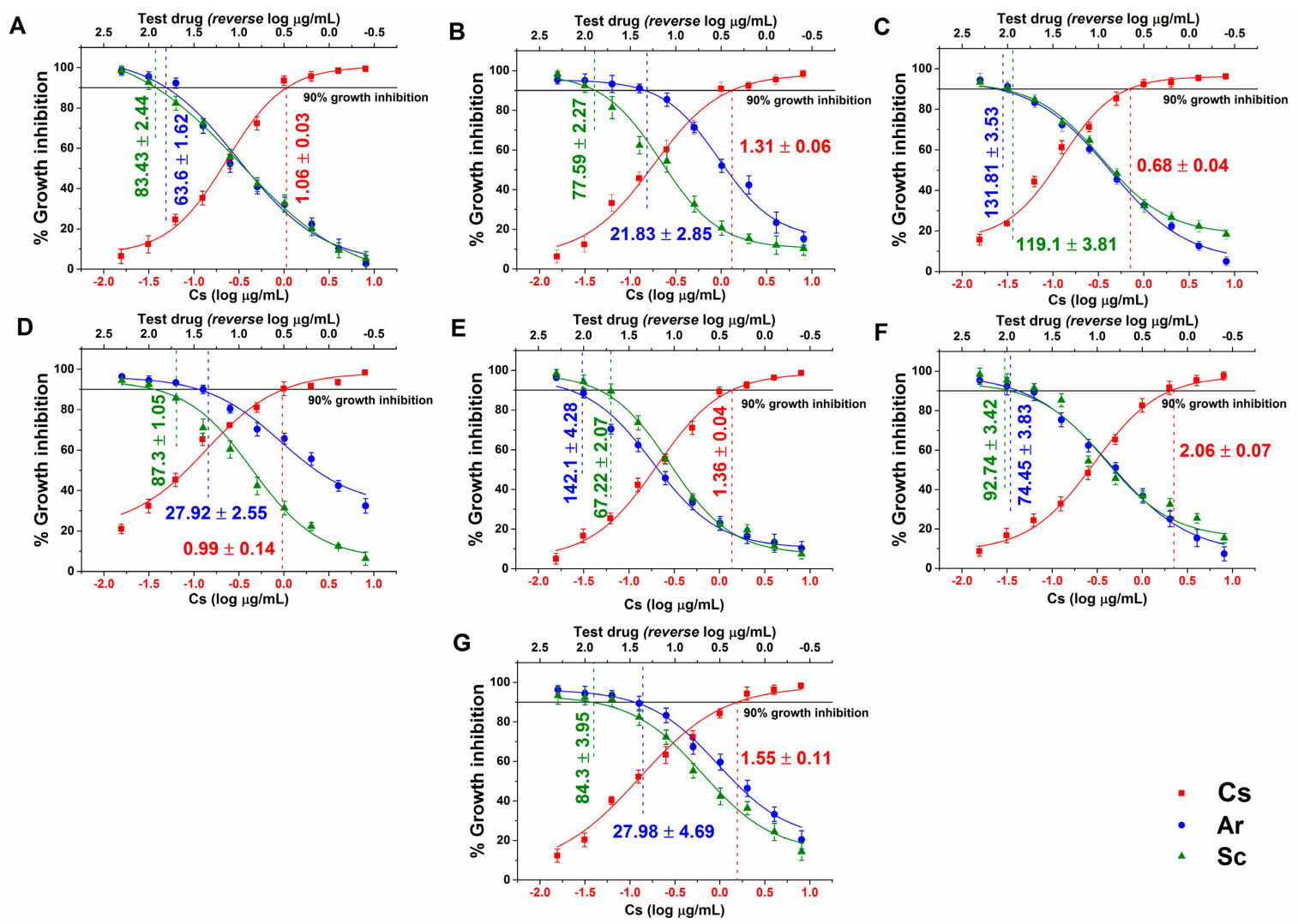

- Cs
- Ar
$-\quad$ Sc

Figure 1. Minimum inhibitory concentrations $\left(\mathrm{MIC}_{90}\right)($ mean $\pm \mathrm{SD})$ of artemisinin $(\mathrm{Ar})$ and scopoletin (Sc) on C. albicans (A), C. dubliniensis (B), C. tropicalis (C), C. krusei (D), C. glabrata (E), C. guilliermondii (F) and C. parapsilosis (G) species. Six independent experiments, each in three replicates, compared with caspofungin (Cs) as positive control and comparison of Ar and Sc treatments $(\mu \mathrm{g} / \mathrm{mL})$.

\subsection{Data of Minimum Effective Concentrations $\left(M E C_{10}\right)$ for Planktonic Candida Species}

Dose-response curves regarding the minimum effective concentrations $\left(\mathrm{MEC}_{10}\right)$ for $\mathrm{Ar}$ and $\mathrm{Sc}$ on the selected opportunistic Candida species are shown in Figure 2. For Ar the obtained $\mathrm{MEC}_{10}$ concentrations are as follows: C. albicans $84.04 \pm 2.92 ;$ C. dubliniensis $71.26 \pm 3.81$; C. tropicalis $89.95 \pm 3.62 ;$ C. $\mathrm{krusei}$ $233.14 \pm 4.72 ;$ C. glabrata $324.97 \pm 4.42 ;$ C. guilliermondii $180.9 \pm 3.36$; and C. parapsilosis $171.86 \pm 4.24$ (in $\mu \mathrm{g} / \mathrm{mL}$ ). For $\mathrm{Sc}$ the $\mathrm{MEC}_{10}$ values were: C. albicans $132.17 \pm 4.19 ;$ C. dubliniensis $132.17 \pm 5.08$; C. tropicalis $134.27 \pm 4.66 ;$ C. krusei $162.01 \pm 5.03 ;$ C. glabrata 215.38.97 $\pm 5.41 ;$ C. guilliermondii $149.2 \pm 5.32$, and C. parapsilosis $164.7 \pm 5.26$ (in $\mu \mathrm{g} / \mathrm{mL})$. The curves have expressed a dose-dependent cell survival (CFU count) after 60 min exposure to Ar and Sc. The doses corresponding to $\mathrm{MEC}_{10}$ (meaning an average $90 \%$ survival rate of mid-log phased populations, at $\sim 10^{5} \mathrm{CFU} / \mathrm{mL}$ ) were further used to evaluate their effects on planktonic cells and on mature biofilms. Cs, Ar, and Sc have shown an average $\mathrm{MEC}_{10}$ of $6.66 \pm 0.14 \mu \mathrm{g} / \mathrm{mL}, 165.16 \pm 3.87 \mu \mathrm{g} / \mathrm{mL}$, and $160.84 \pm 4.99 \mu \mathrm{g} / \mathrm{mL}$, respectively for the tested planktonic Candida spp. Ar appeared to have the lowest $\mathrm{MEC}_{10}$ in the case of $\mathrm{C}$. dubliniensis $(21.83 \pm 2.85 \mu \mathrm{g} / \mathrm{mL})$, C. krusei $(27.92 \pm 2.55 \mu \mathrm{g} / \mathrm{mL})$, and C. parapsilosis $(27.98 \pm 4.69 \mu \mathrm{g} / \mathrm{mL})$, respectively. 

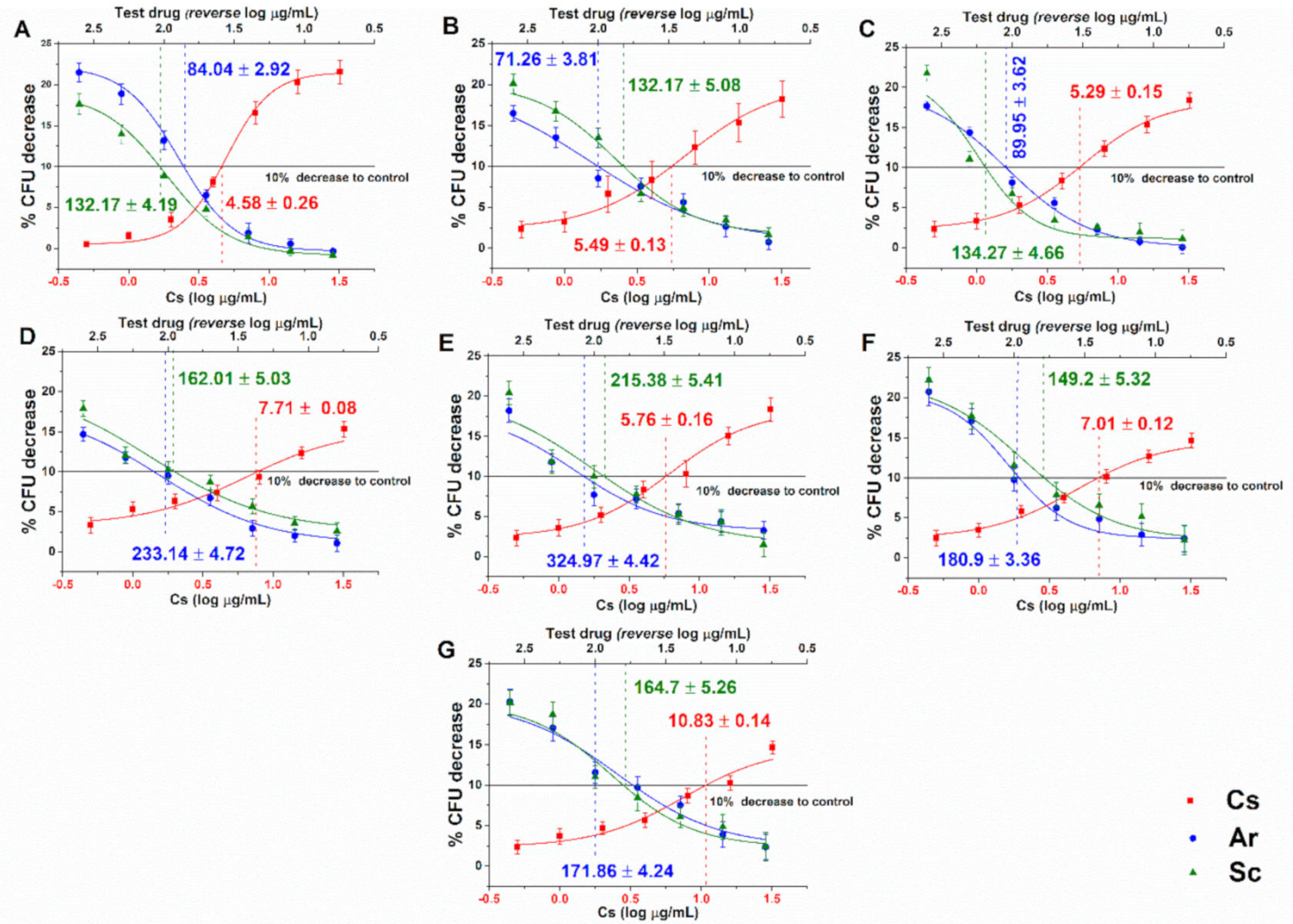

- $\mathrm{Cs}$
- $\mathrm{Ar}$
- Sc

Figure 2. Minimum effective concentrations $\left(\mathrm{MEC}_{10}\right)($ mean $\pm \mathrm{SD})$ of artemisinin $(\mathrm{Ar})$ and scopoletin (Sc) on C. albicans (A), C. dubliniensis (B), C. tropicalis (C), C. krusei (D), C. glabrata (E), C. guilliermondii (F) and C. parapsilosis $(G)$ species. Six independent experiments, each in three replicates, compared with caspofungin (Cs) as positive control and comparison of Ar and Sc treatments $(\mu \mathrm{g} / \mathrm{mL})$.

\subsection{Effects on Mature Biofilms}

A variable response to $\mathrm{Ar}, \mathrm{Sc}$, and $\mathrm{Cs}$ at $\mathrm{MEC}_{10}$ doses have been found. Although no changes in the biomass have been observed in the case of Ar treatments, yet an average $55.04 \pm 9.46 \%$ and $46.32 \pm 12.62 \%$ reduction in metabolic activities and non-viable cells were seen in the case of C. albicans, C. dubliniensis, C. tropicalis, and C. glabrata when compared to growth control $(p<0.01)$. A significant reduction up to an average of $60 \%$ in the total biomass on Sc-treated $C$. albicans, $C$. dubliniensis and $C$. glabrata $(p<0.01)$ was found when compared with growth control (Gc) and Cs treatments. However, the data obtained from metabolic activity testing and non-viable cell numbers are invalid for the above species because of the significant biomass loss. C. guilliermondii has shown significantly higher resistance to Ar and Sc compared with the other species. The highest cell death $(>60 \%)$ detected by the double fluorescence staining assay and the reduced metabolic activities $(<50 \%)$ for C. krusei, and C. parapsilosis were found in the case of Sc treatment (Figure 3). 

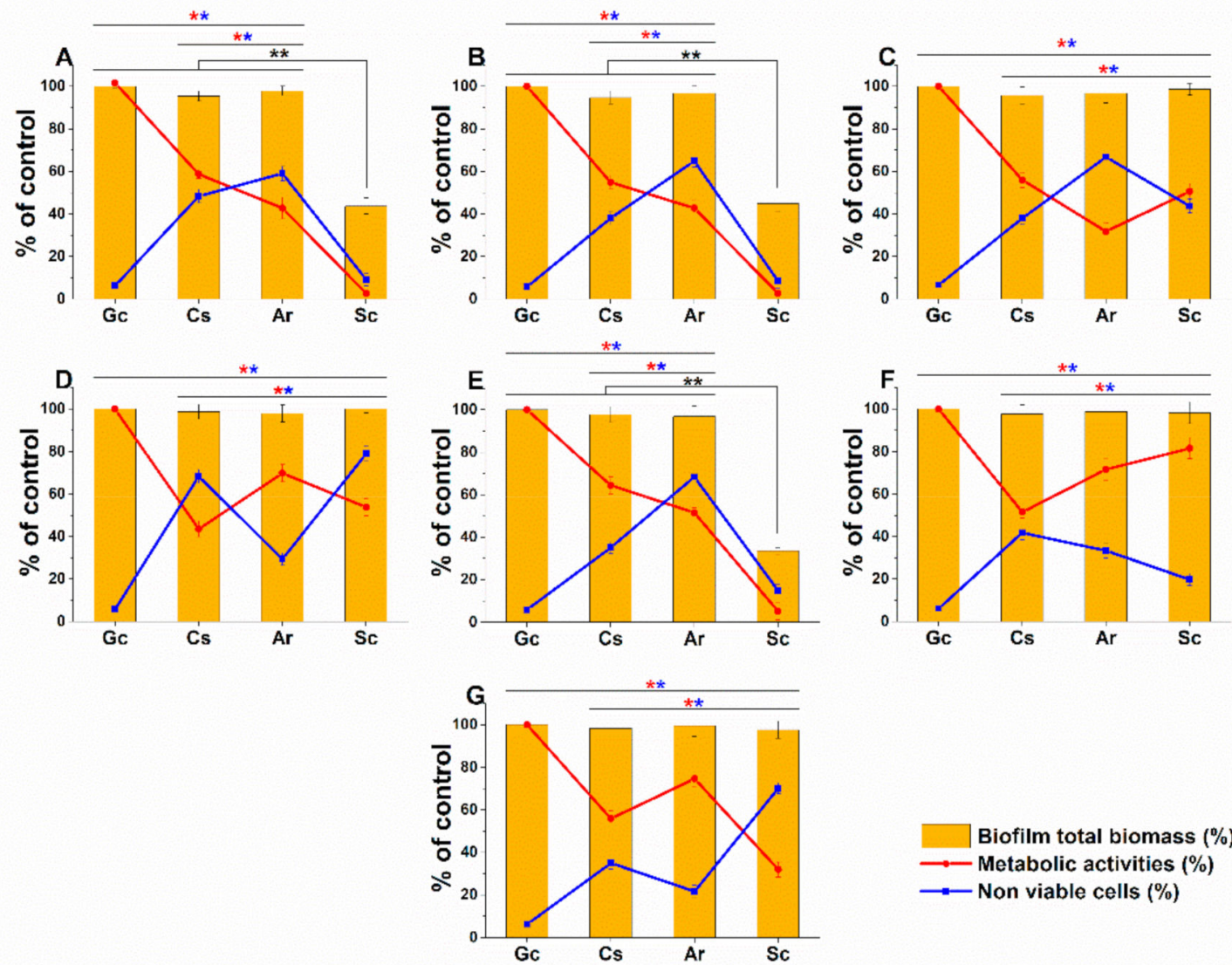

Figure 3. Effects of artemisinin (Ar) and scopoletin (Sc) at their $\mathrm{MEC}_{10}$ concentrations on the metabolic activity, amount of biofilm biomass, and viability of C. albicans (A), C. dubliniensis (B), C. tropicalis (C), C. krusei (D), C. glabrata (E), C. guilliermondii $(\mathbf{F})$, and C. parapsilosis $(\mathbf{G})$ cell populations (mean $\pm \mathrm{SD}, \mathrm{n}=$ 6 independent experiments, data were compared with untreated controls (Gc) and with caspofungin (Cs)-treated positive controls. The red $\left(^{*}\right)$ and blue $\left(^{*}\right)$ asterisks represent a significance value of $p<$ 0.01 for the metabolic activity and viability measurements, respectively. Whereas, the black double asterisks $\left(^{* *}\right)$ highlight the changes in the Sc-treated biofilm biomass when compared to Gc, Cs, and $\mathrm{Ar}$ treatments at $p<0.01$ significance level.

\subsection{Live/Dead Planktonic Cell Viability Discrimination}

The long-term effects of Ar and Sc on the viability were tested on mid-log phased planktonic Candida spp. as well. Ar and Sc decreased the viability of the tested Candida spp. with an average viability reduction of $58.2 \pm 3.5 \%$ and $58.6 \pm 4.2 \%$ after $8 \mathrm{~h}$, whereas $33.6 \pm 3.9 \%$ and $32.2 \pm 3.6 \%$ were seen after $16 \mathrm{~h}$ when compared with their respective controls. C. glabrata, C. guilliermondii, and C. parapsilosis were found to have less than 30\% of viable cells in the presence of Ar and Sc for $16 \mathrm{~h}$ at their $\mathrm{MEC}_{10}$ concentrations. Ar and Sc showed a reduction in viability $\leq 50 \%$ after $8 \mathrm{~h}$ of treatment on C. parapsilosis and C. krusei compared with the controls (Figure 4). 
A
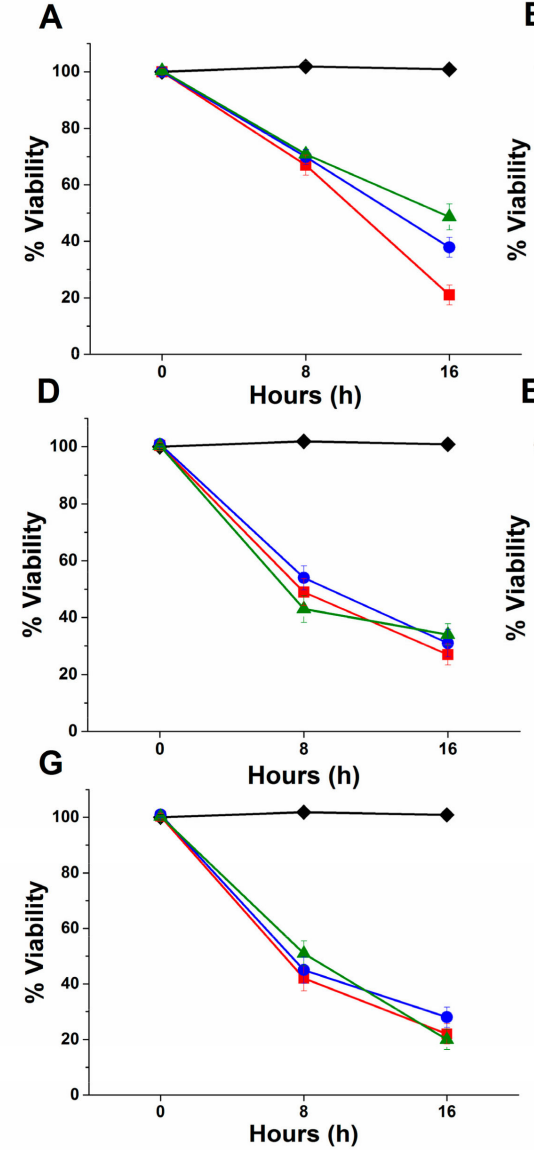

B
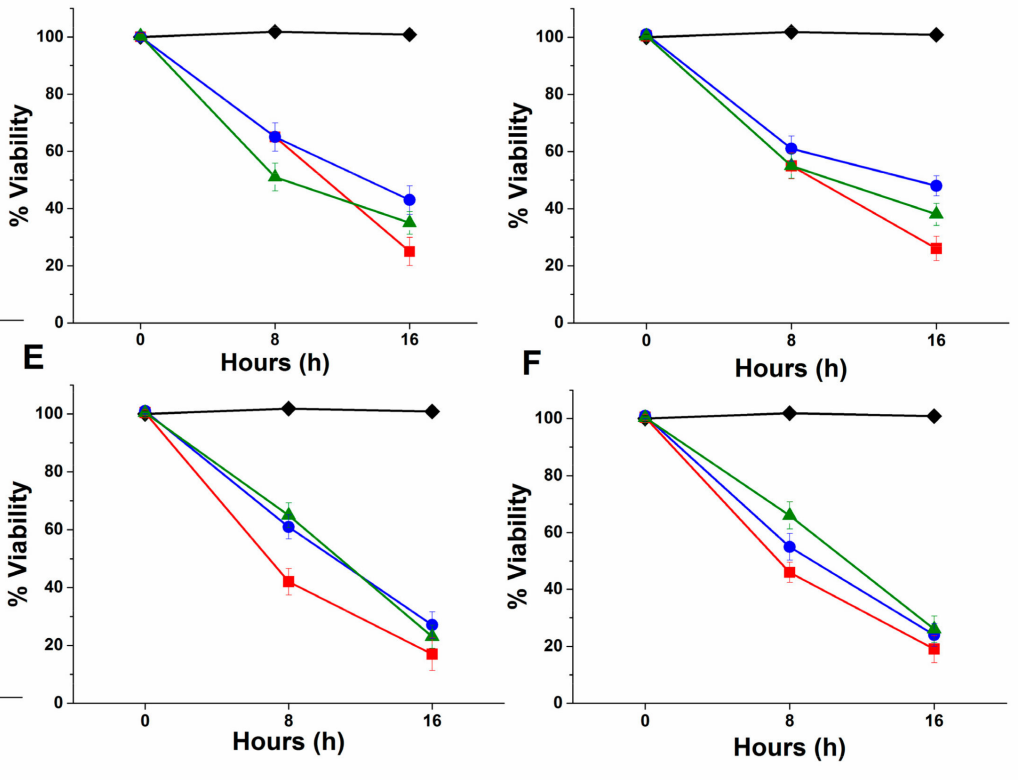

Figure 4. Effects of artemisinin (Ar) and scopoletin (Sc) at their $\mathrm{MEC}_{10}$ concentrations on the viability of planktonic C. albicans (A), C. dubliniensis (B), C. tropicalis (C), C. krusei (D), C. glabrata (E), C. guilliermondii $(\mathbf{F})$, and C. parapsilosis (G) species compared with untreated controls (Gc) after 8 and 16 h of treatment (mean $\pm \mathrm{SD}, \mathrm{n}=6$ independent experiments, caspofungin (Cs) was used as positive control).

\subsection{Effects on Metabolic Activity and on Colony Formation of Planktonic Cells}

The metabolic activity of the mid-log phased planktonic Candida spp. in the presence of Ar and Sc at their $\mathrm{MEC}_{10}$ concentrations was evaluated with resazurin at 0,8 , and $16 \mathrm{~h}$ time points (Figure 5). Ar and Sc showed an average reduction in the metabolic activities of tested Candida spp. to two-fold after $8 \mathrm{~h}$ of treatment followed by three-fold after $16 \mathrm{~h}$ of treatment when compared with their respective controls. A less than two-fold decrease of metabolic activity was found in C. glabrata, C. guilliermondii, and C. parapsilosis planktonic cells in the presence of Ar and Sc after $16 \mathrm{~h}$ of treatment.

A significant change in the planktonic cell number reduction compared with the control $(p<0.01)$ was also found after 8 and $16 \mathrm{~h}$ of treatment (Figure 6). A prominent reduction $\leq 50 \%$ of planktonic cell population, when compared to the controls, was found in the case of $C$. glabrata, $C$. guilliermondii and $C$. parapsilosis after $16 \mathrm{~h}$ of $\mathrm{Ar}, \mathrm{Sc}$, and caspofungin (Cs) exposures. 

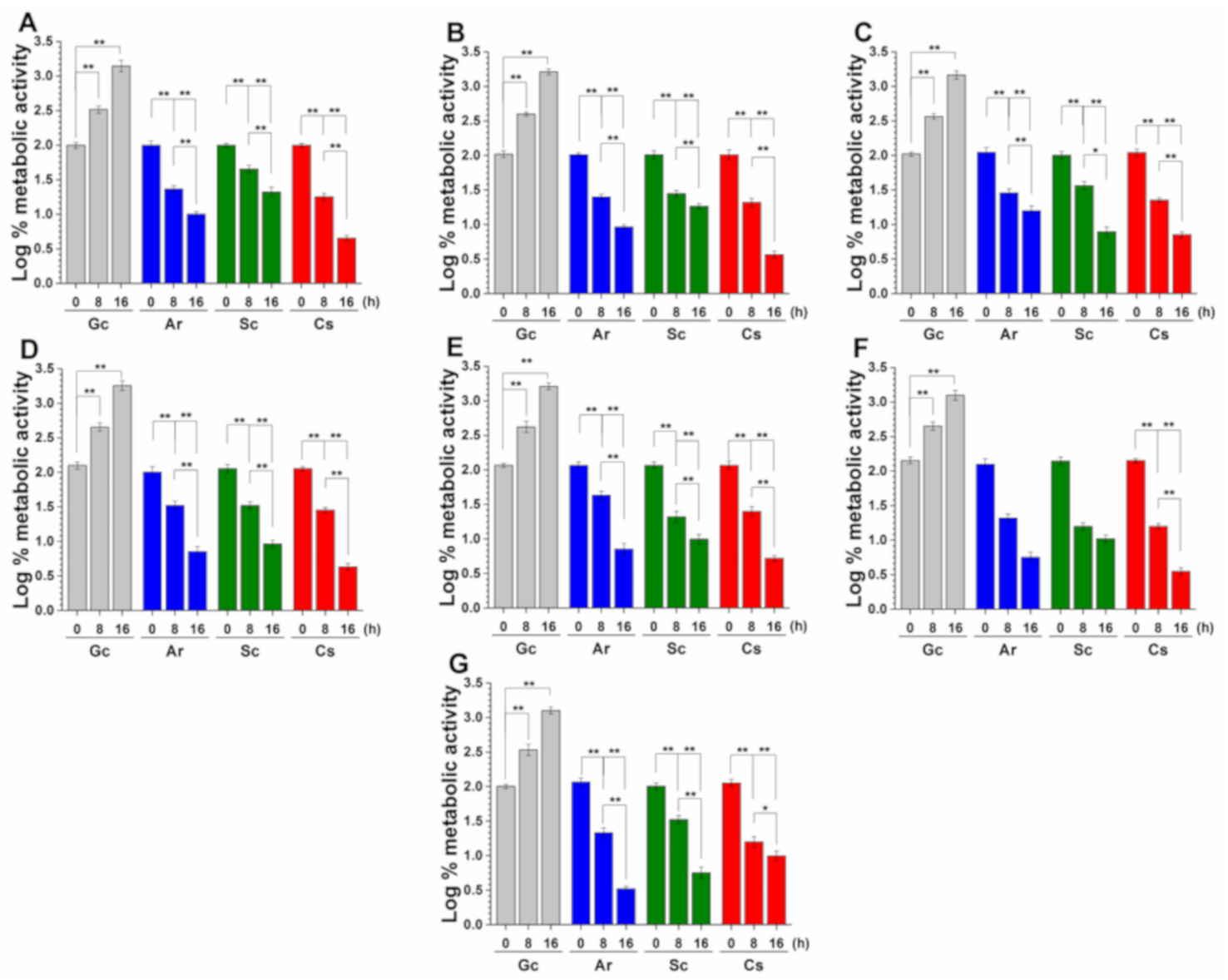

Figure 5. Effects of artemisinin (Ar) and scopoletin (Sc) at their $\mathrm{MEC}_{10}$ concentrations on the metabolic activities of planktonic C. albicans (A), C. dubliniensis (B), C. tropicalis (C), C. krusei (D), C. glabrata (E), C. guilliermondii (F), and C. parapsilosis (G) species compared with untreated controls (Gc) and caspofungin $(\mathrm{Cs})$ as positive control after 8 and $16 \mathrm{~h}$ of treatment (mean $\pm \mathrm{SD}, \mathrm{n}=6$ independent experiments, ${ }^{*} p<0.05$ and $\left.{ }^{* *} p<0.01\right)$.

\subsection{Effects on Planktonics' Oxidative Balance}

The effects of Ar and Sc on the induction of the oxidative stress at $\mathrm{MEC}_{10}$ concentrations on respective mid-log phased Candida spp. planktonic cell populations are illustrated in Figure 7. Menadione (Me) was used as positive control. All the test drugs caused a significant oxidative stress in the planktonic cells compared with that of the controls $(p<0.01)$. More than $25 \%$ and $50 \%$ of $\mathrm{O}_{2}{ }^{\bullet-}$ generation was observed in C. glabrata, C. guilliermondii, and C. parapsilosis compared with other tested Candida spp. after the treatment with Ar and Sc for $16 \mathrm{~h}$. The overall $\mathrm{O}_{2}{ }^{\bullet-}$ generation induced by $\mathrm{Ar}$ was found to be $13.4 \pm 1.8 \%$ higher than that of Sc. Peroxide generation in C. glabrata, C. guilliermondii, and C. parapsilosis was also found to be higher (an average of $30.2 \%$ increment in Ar treatment and $8.4 \%$ increment in Sc treatment) compared with the other tested Candida spp. An average increment of $64.1 \pm 2.6 \%$ was found in oxidative stress induction by Ar when compared to Sc in Candida species. In summary, we found that all the tested Candida species were susceptible to Ar and Sc treatments in favor of Ar vs. Sc. 

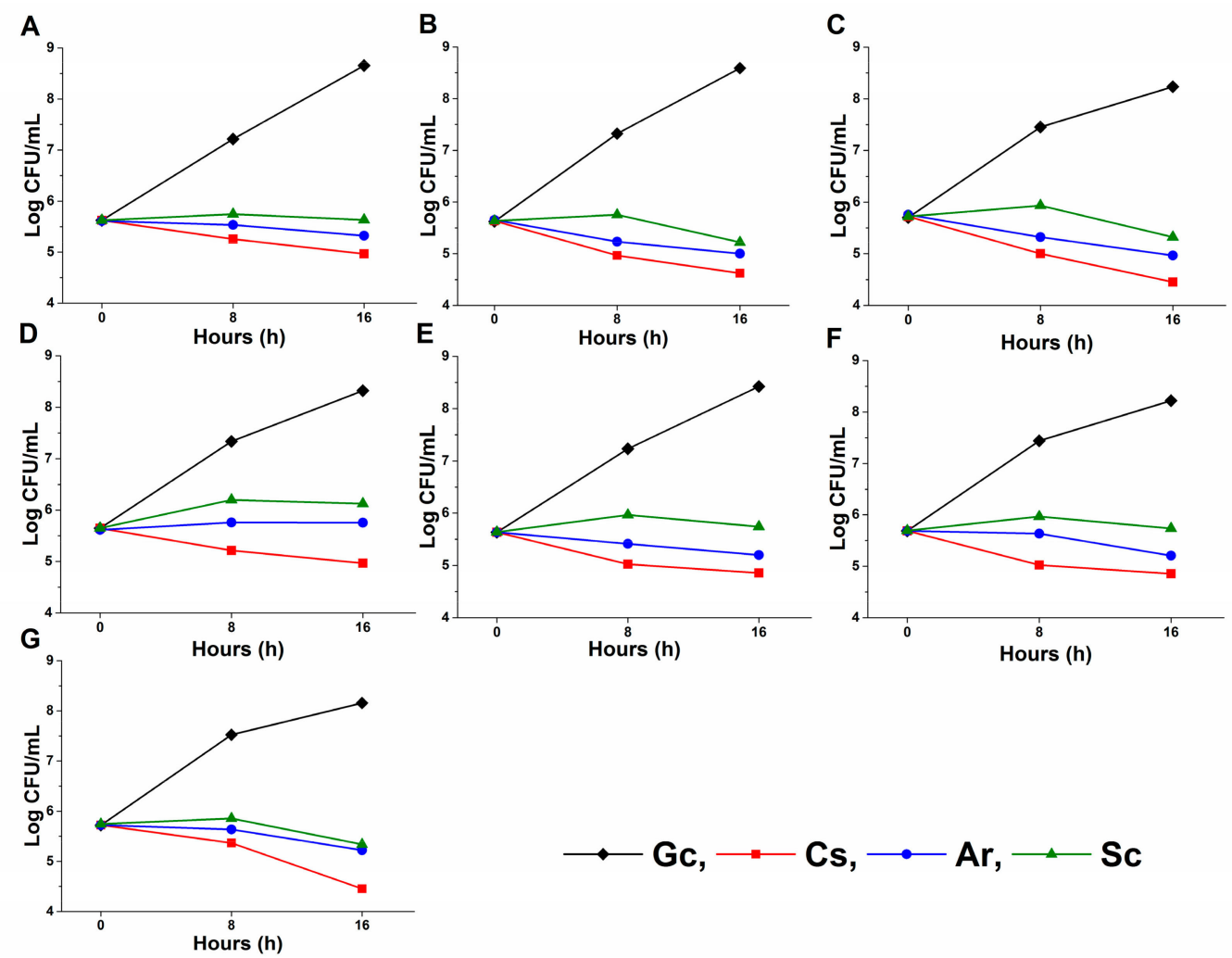

Figure 6. Effects of artemisinin (Ar) and scopoletin (Sc) at their $\mathrm{MEC}_{10}$ concentrations on colony formation of planktonic C. albicans (A), C. dubliniensis (B), C. tropicalis (C), C. krusei (D), C. glabrata (E), C. guilliermondii $(\mathbf{F})$ and C. parapsilosis $(\mathbf{G})$ species compared with untreated controls $(\mathrm{Gc})$ after 8 and 16 h of treatment (mean $\pm \mathrm{SD}, \mathrm{n}=6$ independent experiments, caspofungin (Cs) was used as positive control).
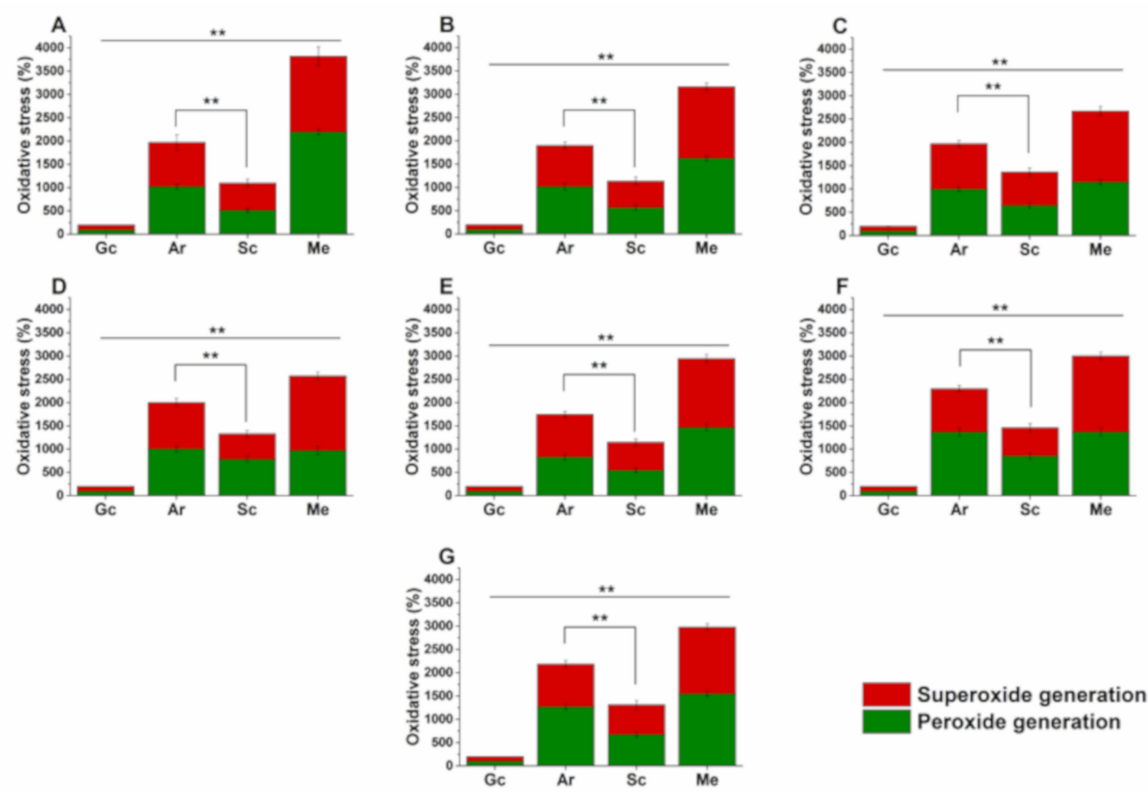

Superoxide generation Peroxide generation

Figure 7. Effects of artemisinin (Ar) and scopoletin (Sc) at their $\mathrm{MEC}_{10}$ concentrations on peroxides $\left(\mathrm{O}_{2}{ }^{2-}\right)$ and superoxide anion $\left(\mathrm{O}_{2}{ }^{\bullet-}\right)$ generation in planktonic C. albicans (A), C. dubliniensis (B), C. tropicalis (C), C. krusei (D), C. glabrata (E), C. guilliermondii (F), and C. parapsilosis (G) species compared with untreated (Gc), with menadione (Me)-treated controls and comparison of Ar and Sc treatments (mean \pm SD, $n=6$ independent experiments, $\left.{ }^{* *} p<0.01\right)$. 


\section{Discussion}

Ar and Sc were effective against the selected Candida spp. and their antifungal activities were comparable in every measured parameter to $\mathrm{Cs}_{\text {even }}$ if the antifungal agent's $\mathrm{MIC}_{90}$ value was much lower than that of our plant-derived test compounds. The susceptibility of selected Candida spp. to Ar and Sc has not been reported before. The antifungal activity of Ar and Sc may be attributed to the inhibition of efflux pumps as it was shown for berberine, a natural isoquinoline alkaloid [18]. The measured lower effects of $S_{c}$ is not known, however, the presence of efflux pump proteins belonging to ABC (ATP Binding Cassette) and MFS (Major Facilitators) superfamily might also be the responsible factors $[18,19]$.

The resazurin assay and SYBR green I-propidium iodide double-stain fluorescent method enabled us to characterize both the planktonic cell populations and biofilms after the treatment with Ar and Sc. As a limitation of our viability study, it should be mentioned that measuring a single parameter only (e.g., the resazurin assay) does not necessarily reflect total cell viability because cellular ATP levels may change rapidly without significant reduction in intracellular enzyme activities [20]. Based on literature data both Ar and Sc may induce time-dependent cell wall and membrane damage enabling propidium iodide to bind to fungal nucleic acids [21]. The double-stain fluorescence assay showed that the longer the exposure time is, the higher cellular death rate is found in the Ar and Sc-treated fungal populations. The difference in viability among the examined Candida species we think is due to the potential difference in the activity of multidrug efflux pumps among the Candida spp. The maintenance of metabolic activities at about $50 \%$ even in the presence of low planktonic cell populations indicates the adaption of surviving planktonic cells [22].

Data presented in this study suggest the induction of apoptosis-like processes in the tested Candida spp. that may be due to the accumulation of reactive oxygen species (ROS) that induce or regulate the apoptosis in yeasts $[23,24]$. Using the superoxide and peroxide radicals' fluorescent assays, we showed the accumulation of reactive oxygen species, which are the indicators of lipid damage [25]. It has been postulated that Ar and Sc affect ergosterol synthesis [19,26]. Ergosterol, apart from maintenance and regulation of structural and functional integrity of the membrane, inhibits lipid peroxidation [27]. This can also facilitate the permeability of the cell membrane and incorporation of propidium iodide through the compromised membranes into the cells. Further characterization of the effects of Ar and Sc on the levels of superoxide dismutase and catalase at increased ROS level must be assessed [26,28]. Moreover, Ar also plays an important role in the electron transport chain by overexpressing nuclear distribution protein nude homolog $1\left(N D E_{1}\right)$ that is responsible for encoding mitochondrial NADH dehydrogenases causing sensitivity to Ar followed by membrane disruption resulting in mitochondrial dysfunction by the higher free radical generation when compared to Sc [29,30].

In this study, we have further investigated the effects of Ar and Sc on the preformed mature biofilms of different Candida spp. Our results demonstrated that Ar is more effective in disrupting the preformed complexed, extracellular matrix-covered biofilm structure and killing the sessile (surface-attached) cell population as well compared to $\mathrm{Sc}$ at their respective $\mathrm{MEC}_{10}$ concentrations after $24 \mathrm{~h}$ exposure. This may be due to the abilities of the sesquiterpenoids to have action on amyloid proteins, which are one of the major building blocks of microbial biofilms [31-34]. On the other hand, Sc treatment showed a dramatic decrement in the total biomass including cell loss from the polystyrene surface in case of $C$. albicans, C. dubliniensis, and C. glabrata, which might be due to the action of coumarin derivatives on the chemical pathways such as quorum sensing resulting in biofilm dispersion [35-40]. However, the higher metabolic activities and the less cell death rate found in the case of $C$. gulliermondii indicates the presence of other drug resistance mechanism factors apart from poor drug penetration into Candida biofilms. The alternate mechanism might be related to the expression patterns of genes coding for multidrug efflux pumps $[22,41,42]$. Moreover, this might be the reason why the surviving cells can adapt to the stressful microenvironment by decreasing their metabolic activities [23,43]. Though the adapted cell populations with reduced metabolic activities might survive the toxicity of both test drugs, Ar exerts higher cell killing properties than those of Sc in the mature biofilm, whereas Sc might cause 
changes in the biofilm adherence factors to the polystyrene surfaces. Adaptation of Candida species under various conditions has already been described [23,44].

Based on the results of the tested Candida planktonic cells, we found that the $\mathrm{MEC}_{10}$ concentrations of our treating compounds are more effective to initiate oxidative imbalance and reducing metabolic activities followed by death of the planktonic cells when compared to the effects on preformed mature biofilms, which have shown variable results including cell death, biomass loss, and resistance. The reason behind the resistance to the $\mathrm{MEC}_{10}$ concentrations maybe due to the extracellular matrix acting as a diffusion barrier $[39,45,46]$ or the up-regulations of the genes coding the efflux pumps [47-49]. Previous studies also reported that the planktonic cells released from the biofilms express subtle genetic changes for producing resistant phenotypes. As a consequence, the resistant new population may form biofilms with altered phenotype that might be responsible for the hostility in some of the tested Candida species [50].

The widely accepted crystal violet assay was used to investigate the effects of the tested compounds on the changes of Candida biofilm biomass [51]. This chemically basic dye stains fungal cells including negatively charged surface molecules and polysaccharides in the biofilm extracellular matrix enabling a rapid quantification of biofilm mass prior to labor-intensive microscope analysis [52]. Although, the poor correlation between the biofilm biomass reduction, metabolic activities and cellular viability remains a major limitation of this method because of the non-selective staining of the biofilm matrix including viable and dead cells as well [53]. Therefore, results obtained from the crystal violet assay must be combined with other multi-parametric techniques such as intracellular ATP, ATP/protein ratio, live/dead cell discrimination and selective visualization of the biomass matrix [54-56].

Our novel multi-parametric evaluations have more precisely highlighted the planktonic fungal susceptibility, killing ability inside the mature biofilm than the classical proliferation assays [57-60]. The observed antifungal effects and combined actions on mature biofilms of Ar and Sc might be useful for further detailed research for their potential usage as alternative antimicrobial agents for the treatment of Candida infections.

\section{Materials and Methods}

\subsection{Materials}

For our experiments, sterile 96-well microtiter plates for antifungal activity, live/dead discrimination and metabolic assays (Catalog number: 30096, SPL Life Sciences Co. Ltd., Gyeonggi-do, Korea), and for biofilm assays (Catalog number: 83.3924.500, Sarstedt AG \& Co. KG, Numbrecht, Germany), crystal violet, peptone, yeast extract, agar-agar, potassium phosphate monobasic, acetic acid (Reanal Labor, Budapest, Hungary), resazurin, modified RPMI 1640 medium (containing 3.4\% $(\mathrm{w} / \mathrm{v})$ MOPS, $1.8 \%(\mathrm{w} / \mathrm{v})$ dextrose and $0.002 \%(\mathrm{w} / \mathrm{v})$ adenine) [61], menadione (Me), artemisinin (Ar), scopoletin (Sc), SYBR green I 10,000x, propidium iodide, dihydrorhodamine 123 (DHR 123) and dihydroethidine (DHE) (Sigma-Aldrich Chemie GmbH, Steinheim, Germany), disodium phosphate, dimethyl sulfoxide (DMSO) from Chemolab Ltd. (Budapest, Hungary), sodium chloride (VWR Chemicals, Debrecen, Hungary), dextrose, adenine, potassium chloride (Scharlau Chemie S.A, Bercelona, Spain), 3-(N-morpholino) propanesulfonic acid (MOPS) (Serva Electrophoresis GmbH, Heidelberg, Germany), $0.22 \mu \mathrm{m}$ vacuum filters from Merck Millipore (Molsheim, France) were used. All other chemicals in the study were of analytical or spectroscopic grade. Highly purified water $(<1.0 \mu \mathrm{S})$ was applied throughout the experiments. Caspofungin (Cs) was purchased from Merck Sharp \& Dohme Ltd. (Hertfordshire, UK).

\subsection{Instruments Used in the Experiments}

A microbiological incubator (Thermo Scientific Heraeus B12, Auro-Science Consulting Kft., Budapest, Hungary), microtiter plate reader (PerkinElmer EnSpire Multimode plate reader, 
Auro-Science Consulting Ltd., Budapest, Hungary), benchtop centrifuge (Hettich Rotina 420R, Auro-Science Consulting Kft., Budapest, Hungary) were used throughout the experiments.

\subsection{Microorganisms and Culture Conditions}

All the fungal species were obtained from Szeged Microbiology Collection, University of Szeged, Hungary (Table 1) and were maintained at the Department of General and Environmental Microbiology, Institute of Biology, University of Pécs, Hungary. C. albicans 1372, C. dubliniensis 1470, C. tropicalis 1368, C. krusei 779, C. glabrata 1374, C. guilliermondii 808, and C. parapsilosis 8006 were used to evaluate the $\mathrm{MIC}_{90}$, the minimum effective concentration $\left(\mathrm{MEC}_{10}\right)$ for the planktonic cells and the inhibition of biofilm formation of the test samples. All the fungal species were cultured and maintained in yeast extract peptone dextrose agar medium (YPD: $1 \%(\mathrm{w} / \mathrm{v})$ peptone, $0.5 \%(\mathrm{w} / \mathrm{v})$ yeast extract, $2 \%(\mathrm{w} / \mathrm{v})$ dextrose, $1.5 \%(\mathrm{w} / \mathrm{v})$ agar-agar in distilled water [62]. Phosphate-buffered saline (PBS, pH 7.4) was from Life Technologies Ltd. (Budapest, Hungary), and highly purified water $(<1.0 \mu \mathrm{S})$ was applied throughout the experiments.

Table 1. Candida species examined in the study.

\begin{tabular}{ccc}
\hline Species & Collection Code & Origin \\
\hline C. albicans & SZMC 1372 & clinical sample/Debrecen, Hungary \\
\hline C. dubliniensis & CBS 7987 & oral cavity of HIV-infected patient/Melbourne, \\
SZM 1470 & Australia \\
\hline C. tropicalis & SZMC 1368 & clinical sample/Debrecen, Hungary \\
\hline C. krusei & SZMC 0779 & $\begin{array}{c}\text { clinical sample/National Institute of } \\
\text { Environmental Health (NIEH), Hungary }\end{array}$ \\
\hline C. glabrata & SZMC 1374 & clinical sample/Debrecen, Hungary \\
\hline C. guilliermondii & SZMC 0808 & clinical sample/Pécs, Hungary \\
\hline C. parapsilosis & SZMC 8006 & clinical sample/Szeged, Hungary \\
\hline
\end{tabular}

Abbreviations: SZMC, Szeged Microbiological Collection, Szeged, Hungary (http://www.wfcc.info/ccinfo/collection/by id/987); CBS, Westerdijk Fungal Biodiversity Institute, Utrecht, The Netherlands (http://www.westerdijkinstitute.nl/).

\subsection{Determination of Minimum Inhibitory Concentration ( $M I C_{90}$ )}

The $\mathrm{MIC}_{90}$ was performed according to a previously published method [63] with modifications. Ar and Sc were prepared in DMSO at concentrations ranging from $0.39-200 \mu \mathrm{g} / \mathrm{mL}$ and $0.01-8 \mu \mathrm{g} / \mathrm{mL}$ for Cs. Total of $100 \mu \mathrm{L}$ of fungal suspensions of $10^{3}$ colony forming units (CFU)/mL in modified RPMI 1640 medium was pipetted into each well of sterile 96-well microtiter plates and mixed with $100 \mu \mathrm{L}$ of dilutions of Ar and Sc. The final solvent concentration for the dilution of the drugs was restricted up to $2.5 \% \mathrm{v} / \mathrm{v}$ in the wells. Inoculated growth medium without any treatment was considered as the growth control. The sterile medium was taken as the blank. After $48 \mathrm{~h}$ of incubation at $30{ }^{\circ} \mathrm{C}$ in a microbiological incubator, the absorbance was measured at $595 \mathrm{~nm}$. Absorbance values were converted to percentages compared with those of the growth control $(\approx 100 \%)$ and data were fitted by non-linear dose-response curve method to calculate the dose producing $\geq 90 \%$ growth inhibition $\left(\mathrm{MIC}_{90}\right)$. All the measurements were performed by applying three technical replicates in six independent experiments. Cs was used as a standard antifungal drug throughout the experiments.

\subsection{Determination of Minimum Effective Concentration $\left(M E C_{10}\right)$}

The $\mathrm{MEC}_{10}$ measurement was performed according to our previously published protocol to estimate the dose-dependent survival rate of the cells [64-66] with modifications. Briefly, Ar and Sc were prepared in DMSO at concentrations ranging from $0.25-400 \mu \mathrm{g} / \mathrm{mL}$ and $0.5-32 \mu \mathrm{g} / \mathrm{mL}$ for Cs. Total of $100 \mu \mathrm{L}$ of fungal suspensions of mid-log phased $10^{5}$ colony forming unit (CFU)/mL in modified RPMI 1640 medium were pipetted into each well of sterile 96-well microtiter plates and 
mixed with $100 \mu \mathrm{L}$ of dilutions of Ar and Sc. The final solvent concentration for the dilutions of the drugs was restricted up to $2.5 \%(\mathrm{v} / \mathrm{v})$ in the wells. Inoculated growth medium without any treatment was considered as the growth control. The sterile medium was taken as the blank. After $60 \mathrm{~min}$ of incubation at $30{ }^{\circ} \mathrm{C}$ in a microbiological incubator, $1 \mathrm{~mL}$ of treated and untreated samples was pipetted and were spread in nutrient agar media for $24 \mathrm{~h}$ at $30^{\circ} \mathrm{C}$ for colony-forming unit $(\mathrm{CFU} / \mathrm{mL})$ quantification. $\mathrm{CFU} / \mathrm{mL}$ values were converted to percentages and data were fitted with a non-linear dose-response curve to achieve drug concentrations producing an approximately $90 \%$ fungal cell growth $\left(\mathrm{MEC}_{10}\right)$ compared to the untreated culture after one hour treatment. All the measurements were performed by applying three technical replicates in six independent experiments. Cs was used as a standard antifungal drug throughout the experiments.

\subsection{Determination of the Effects on Preformed Mature Biofilms}

The protocol for the measurement of the effects on the mature biofilms and treatment was adapted from the literature $[7,67]$ with modifications. Total of $200 \mu \mathrm{L}$ samples of $24 \mathrm{~h}$ old late-log phased $C$. albicans and non-albicans species in the modified RPMI 1640 medium $\left(10^{6} \mathrm{CFU} / \mathrm{mL}\right)$ were used to culture biofilms without treatments for $24 \mathrm{~h}$ at $30^{\circ} \mathrm{C}$. The microtiter plates were washed carefully with sterile PBS (pH. 7.4) and were re-incubated with $200 \mu \mathrm{L}$ culture medium containing Ar and Sc to be examined at $\mathrm{MEC}_{10}$ concentrations $(\mu \mathrm{g} / \mathrm{mL})$ for further $24 \mathrm{~h}$ at $30^{\circ} \mathrm{C}$. Modified RPMI media as blank, inoculated growth media as growth control (Gc) and Cs-treated samples were considered as controls throughout the experiments. The percentage (\%) of inhibition was measured based on the comparison of the values with those of Gc. Treatments were performed with three technical replicates in six independent experiments.

\subsubsection{Evaluation of Total Fungal Biomass in the Biofilms}

To determine the changes in the biofilms, a previously published crystal violet assay protocol was used [36] with modifications. After $24 \mathrm{~h}$ incubation, the crystal violet-stained and PBS-washed biofilms were treated with $200 \mu \mathrm{L}$ of $33 \%$ (v/v) acetic acid in double-distilled water. Finally, after $20 \mathrm{~min}$ the acetic acid-dissolved dye from the biofilm matrix was pipetted into the wells of a new microtiter plate and the absorbance was measured at $590 \mathrm{~nm}$. Cs at $\mathrm{MEC}_{10}$ concentration was used as positive control. The \% biofilm biomass reduction measurement was based on growth control (Gc) values which were assigned to be $100 \%$ fungal biofilm mass. Six independent experiments were done with three technical replicates for each treatment.

\subsubsection{Resazurin-Derived Metabolism Assay in the Biofilms}

A resazurin-based fluorescent assay published by Kerekes et al. was adapted [36] and was used to estimate the metabolically active (viable) cell number in the biofilm matrix treated with Ar and $\mathrm{Sc}$ at $\mathrm{MEC}_{10}$ concentrations. Briefly, after $24 \mathrm{~h}$ of treatment, the supernatants were removed and the wells were rinsed with PBS. Resazurin $(12.5 \mu \mathrm{mol} / \mathrm{L})$ in $200 \mu \mathrm{L}$ of sterile PBS was added to each well containing the biofilm. After $40 \mathrm{~min}$ of incubation at $30^{\circ} \mathrm{C}$, the fluorescence was measured at excitation and emission wavelengths of 560/590 nm respectively. The \% metabolic activity measurement was estimated based on the growth control (Gc) fluorescence values which were considered to be $100 \%$. The PBS was taken as blank throughout the experiments. Six independent experiments were performed with three technical replicates for each treatment.

\subsubsection{Viability Assay of the Biofilms and of Planktonic Candida Species}

For determination of live/dead microbes in the preformed mature biofilms we followed the method previously published [63]. Briefly, after $24 \mathrm{~h}$ of treatment with $\mathrm{Ar}$, Sc, and $\mathrm{Cs}$ (positive control) at $\mathrm{MEC}_{10}$ concentrations in the wells of a microplate, the modified RPMI 1640 medium and the non-attached planktonic cells were removed, and the wells were rinsed and filled with $100 \mu \mathrm{L}$ PBS. A working dye solution containing $20 \mu \mathrm{L}$ SYBR green I (from 10,000× stock in DMSO, diluted 100 times in PBS) and 
$4 \mu \mathrm{L}$ propidium iodide (500-fold dilution of working stock in DMSO prepared from $20 \mathrm{mmol} / \mathrm{L}$ in DMSO) in $1000 \mu \mathrm{L}$ of PBS was used. A total of $100 \mu \mathrm{L}$ of this working solution was added into the wells of the microplate. The plates were incubated at room temperature in the dark with mild shaking for $15 \mathrm{~min}$.

For the evaluation of the long-term effects of $\mathrm{Ar}, \mathrm{Sc}$, and $\mathrm{Cs}$ at their $\mathrm{MEC}_{10}$ on the tested Candida spp., a previously published live/dead planktonic cell discrimination [63] was optimized and used. A wide concentration range of SYBR green I (5.5-5500-fold logarithmic dilutions) and propidium iodide (5-500-fold logarithmic dilutions) was examined. For the discrimination of live/dead cells, mid-log phased cell populations of $10^{5} \mathrm{CFU} / \mathrm{mL}$ were treated by Ar and Sc with a dose assigned for $\mathrm{MEC}_{10}$ concentrations and incubated at $30^{\circ} \mathrm{C}$ for $16 \mathrm{~h}$. Sampling was done at 0,8 , and $16 \mathrm{~h}$ time points for the measurements. The samples were centrifuged at $1000 \mathrm{~g}$ for $5 \mathrm{~min}$, washed in PBS and re-suspended in PBS (100 $\mu \mathrm{L}$ in each well). Then $100 \mu \mathrm{L}$ of freshly prepared working dye solution in PBS (using $20 \mu \mathrm{L}$ SYBR green I and $4 \mu \mathrm{L}$ propidium iodide diluted solutions as described earlier) was added to the samples. The plate was incubated at room temperature for $15 \mathrm{~min}$ in the dark with mild shaking.

A PerkinElmer EnSpire multimode plate-reader was used to measure the fluorescence intensities of SYBR green I (excitation/emission wavelengths: 490/525 nm) and propidium iodide (excitation/emission wavelengths: 530/620 nm), respectively. A green to red fluorescence ratio for each sample and for each dose was achieved and the \% of dead cells with the response to the applied dose was plotted against the applied Ar and Sc doses using the previously published formula [63]. In the case of biofilms, the measurements were done by area scan mode of the instrument. All treatments were done in triplicates and six independent experiments were performed.

\subsection{Determination of the Metabolic Activity with Resazurin Assay and Colony Formation of Planktonic Fungal Cells}

The metabolic activity of the cells under treatment conditions was performed by the widely accepted resazurin fluorescence method $[68,69]$. The experiments had to be optimized because the resazurin concentration, the cell number and the incubation time are crucial in order to increase the signal to noise ratio. Fluorescence data were corrected by subtracting background fluorescence (resazurin in PBS). The initial Candida cell density, resazurin levels, and duration of incubation time were varied by using resazurin concentrations ranging from $1.6 \mu \mathrm{mol} / \mathrm{L}$ to $25 \mu \mathrm{mol} / \mathrm{L}$ in the cell suspensions. The proper incubation time for resazurin exposure at an optimized concentration $(12.5 \mu \mathrm{mol} / \mathrm{L}) \mathrm{was}$ performed by $60 \mathrm{~min}$ incubation and sampling at intervals. The appropriate Candida species cell density was obtained by exposing a serial dilution of cells to $12.5 \mu \mathrm{mol} / \mathrm{L}$ resazurin in PBS. PBS without resazurin but with identical cell density to the investigated samples was used as blank.

For fungal colony forming unit measurements, we followed a previously published protocol [70]. Briefly, $1 \mathrm{~mL}$ of untreated and Ar, Sc, and Cs-treated sample was pipetted at 0,8 , and $16 \mathrm{~h}$ time intervals and was diluted $10^{5}$ times followed by spreading $50 \mu \mathrm{L}$ onto $20 \mathrm{~mL}$ YPD agar medium using a cell spreader and incubated at $30^{\circ} \mathrm{C}$ for $24 \mathrm{~h}$. Cs was used as a reference control. Fungal colony forming units $(\mathrm{CFU} / \mathrm{mL})$ were determined, performed in triplicates and were plotted against time (h). Six independent experiments were done with three technical replicates for each treatment.

\subsection{Detection of Peroxide $\left(\mathrm{O}_{2}{ }^{2-}\right)$ and Superoxide Anion $\left(\mathrm{O}_{2}{ }^{\bullet-}\right)$ Generation in Planktonic Fungal Cells}

We adapted the protocols previously described [25] for peroxide anion radicals $\left(\mathrm{O}_{2}{ }^{2-}\right)$ determination and for superoxide detection in the cells [62] with modifications. The final cell population for the experiment was set to mid-log phased $10^{5} \mathrm{CFU} / \mathrm{mL}$. An end concentration of $0.5 \mathrm{mmol} / \mathrm{L}$ of menadione $(\mathrm{Me})$ in cell suspensions was added as the positive control. The cell suspensions were treated with $\mathrm{MEC}_{10}$ concentrations of test samples. The treatments were done for $60 \mathrm{~min}$ at $30^{\circ} \mathrm{C}$ in the modified RPMI 1640 medium. Thereafter, the cells were centrifuged for $5 \mathrm{~min}$ at $1500 \mathrm{~g}$ at room temperature. The pellets were re-suspended in PBS in the same volume. DHR 123 at a final concentration of $10 \mu \mathrm{mol} / \mathrm{L}$ for peroxides determination and $\mathrm{DHE}$ at a final concentration of $15 \mu \mathrm{mol} / \mathrm{L}$ for $\mathrm{O}_{2}{ }^{\bullet-}$ determination 
were added separately to the cell samples. The stained cell samples were further incubated for $60 \mathrm{~min}$ at $30^{\circ} \mathrm{C}$ in the dark condition with mild shaking. The samples were centrifuged and re-suspended in PBS followed by distribution of the samples into the wells of 96-well microplates. The fluorescence was measured at excitation/emission wavelengths of 500/536 nm for peroxides and 473/521 nm for $\mathrm{O}_{2}{ }^{\bullet-}$ detection, respectively by a PerkinElmer EnSpire multimode plate-reader. The percentage increase in oxidative stress was measured by comparing the signals to those of the growth controls. Six independent experiments were done with three technical replicates for each treatment.

\subsection{Statistical Analysis}

All data are given as mean \pm SD. Graphs and statistical analyses were conducted using OriginPro 2016 (OriginLab Corp., Northampton, MA, USA). All experiments were performed independently six times in triplicates and data were analyzed by one-way ANOVA test. $P$-value of $<0.05$ was considered as statistically significant. The minimum inhibitory concentration $\left(\mathrm{MIC}_{90}\right)$ and the minimum effective concentration $\left(\mathrm{MEC}_{10}\right)$ were calculated using a non-linear dose-response curve function as follows:

$$
y=A_{1}+\frac{A_{2}-A_{1}}{1+10^{\left(L O G_{x} 0-x\right) p}}
$$

where, $\mathrm{A}_{1}, \mathrm{~A}_{2}, \mathrm{LOG}_{\mathrm{x}} \mathrm{O}$, and $\mathrm{p}$ are the bottom asymptote, top asymptote, center and hill slope of the curve have been considered.

Author Contributions: Conceptualization T.K., S.D., and N.P.; methodology S.D., L.C., V.B., G.P., Z.G., and T.K.; software, S.D. and V.B.; formal analysis, S.D. and L.C.; investigation, S.D., L.C., and V.B.; resources, T.K. and N.P.; data curation, S.D., L.C., and V.B.; writing — original draft preparation, S.D.; writing - review and editing, T.K.; visualization, S.D. L.C., and V.B.; supervision, T.K.; funding acquisition T.K. All authors have read and agreed to the published version of the manuscript.

Funding: The work was financially supported by University of Pécs, Medical School, KA-2018-17, University of Pécs, Medical School EFOP-3.6.1.-16-2016-00004 and EFOP-3.6.3-VEKOP-16-2017-00009 and NKFI-EPR (Hungarian Scientific Research Fund. K 127944) grants.

Conflicts of Interest: The authors declare no conflict of interest.

\section{References}

1. Wang, X.; van de Veerdonk, F.L.; Netea, M.G. Basic Genetics and Immunology of Candida Infections. Infect. Dis. Clin. N. Am. 2016, 30, 85-102. [CrossRef] [PubMed]

2. De Aguiar Cordeiro, R.; Sales, J.A.; Castelo, D.D.S.C.M.; Brilhante, R.S.N.; de Ponte, Y.B.; dos Santos Araújo, G.; Mendes, P.B.L.; Pereira, V.S.; de Alencar, L.P.; de Queiroz Pinheiro, A.; et al. Candida parapsilosis complex in veterinary practice: A historical overview, biology, virulence attributes and antifungal susceptibility traits. Vet. Microbiol. 2017, 212, 22-30. [CrossRef] [PubMed]

3. Gugnani, H.C.; Denning, D.W. Burden of serious fungal infections in the Dominican Republic. J. Infect. Public Health 2016, 9, 7-12. [CrossRef] [PubMed]

4. Álvarez-Pérez, S.; García, M.E.; Cutuli, M.T.; Fermín, M.L.; Daza, M.Á.; Peláez, T.; Blanco, J.L. Acquired multi-azole resistance in Candida tropicalis during persistent urinary tract infection in a dog. Med. Mycol. Case Rep. 2016, 11, 9-12. [CrossRef] [PubMed]

5. Ostrosky-Zeichner, L.; Sobel, J.D. Fungal Infections. Infect. Dis. Clin. N. Am. 2016, 30, 13-14. [CrossRef]

6. Brilhante, R.S.N.; de Oliveira, J.S.; de Jesus Evangelista, A.J.; Serpa, R.; da Silva, A.L.; de Aguiar, F.R.M.; Pereira, V.S.; Castelo, D.D.S.C.M.; Pereira-Neto, W.A.; de Aguiar Cordeiro, R.; et al. Candida tropicalis from veterinary and human sources shows similar in vitro hemolytic activity, antifungal biofilm susceptibility and pathogenesis against Caenorhabditis elegans. Vet. Microbiol. 2016, 192, 213-219. [CrossRef]

7. Jothiprakasam, V.; Sambantham, M.; Chinnathambi, S.; Vijayaboopathi, S. Candida tropicalis biofilm inhibition by ZnO nanoparticles and EDTA. Arch. Oral Biol. 2017, 73, 21-24. [CrossRef]

8. Armstrong-James, D.; Meintjes, G.; Brown, G.D. A neglected epidemic: Fungal infections in HIV/AIDS. Trends Microbiol. 2014, 22, 120-127. [CrossRef] 
9. Ksiezopolska, E.; Gabaldón, T. Evolutionary Emergence of Drug Resistance in Candida Opportunistic Pathogens. Genes (Basel) 2018, 9, 461. [CrossRef]

10. Efferth, T. From ancient herb to modern drug: Artemisia annua and artemisinin for cancer therapy. Semin. Cancer Biol. 2017, 46, 65-83. [CrossRef]

11. Radulović, N.S.; Randjelović, P.J.; Stojanović, N.M.; Blagojević, P.D.; Stojanović-Radić, Z.Z.; Ilić, I.R.; Djordjević, V.B. Toxic essential oils. Part II: Chemical, toxicological, pharmacological and microbiological profiles of Artemisia annua L. volatiles. Food Chem. Toxicol. 2013, 58, 37-49. [CrossRef] [PubMed]

12. Ho, W.E.; Peh, H.Y.; Chan, T.K.; Wong, W.S.F. Artemisinins: Pharmacological actions beyond anti-malarial. Pharmacol. Ther. 2014, 142, 126-139. [CrossRef]

13. Tzeng, T.; Lin, Y.; Jong, T.; Chang, C. Ethanol modified supercritical fluids extraction of scopoletin and artemisinin from Artemisia annua L. Sep. Purif. Technol. 2007, 56, 18-24. [CrossRef]

14. Liu, W.; Hua, J.; Zhou, J.; Zhang, H.; Zhu, H.; Cheng, Y.; Gust, R. Synthesis and in vitro antitumor activity of novel scopoletin derivatives. Bioorg. Med. Chem. Lett. 2012, 22, 5008-5012. [CrossRef]

15. Moon, P.-D.; Lee, B.-H.; Jeong, H.-J.; An, H.-J.; Park, S.-J.; Kim, H.-R.; Ko, S.-G.; Um, J.-Y.; Hong, S.-H.; Kim, H.-M. Use of scopoletin to inhibit the production of inflammatory cytokines through inhibition of the IкB/NF-кB signal cascade in the human mast cell line HMC-1. Eur. J. Pharmacol. 2007, 555, 218-225. [CrossRef] [PubMed]

16. Galal, A.M.; Ross, S.A.; Jacob, M.; ElSohly, M.A. Antifungal Activity of Artemisinin Derivatives. J. Nat. Prod. 2005, 68, 1274-1276. [CrossRef] [PubMed]

17. Gnonlonfin, G.J.B.; Sanni, A.; Brimer, L. Review Scopoletin-A Coumarin Phytoalexin with Medicinal Properties. Crit. Rev. Plant Sci. 2012, 31, 47-56. [CrossRef]

18. Zorić, N.; Kosalec, I.; Tomić, S.; Bobnjarić, I.; Jug, M.; Vlainić, T.; Vlainić, J. Membrane of Candida albicans as a target of berberine. BMC Complement. Altern. Med. 2017, 17, 268. [CrossRef]

19. Al-Fattani, M.A.; Douglas, L.J. Penetration of Candida Biofilms by Antifungal Agents. Antimicrob. Agents Chemother. 2004, 48, 3291-3297. [CrossRef]

20. Sali, N.; Nagy, S.; Poór, M.; Kőszegi, T. Multiparametric luminescent cell viability assay in toxicology models: A critical evaluation. J. Pharmacol. Toxicol. Methods 2016, 79, 45-54. [CrossRef]

21. Kainz, K.; Tadic, J.; Zimmermann, A.; Pendl, T.; Carmona-Gutierrez, D.; Ruckenstuhl, C.; Eisenberg, T.; Madeo, F. Methods to Assess Autophagy and Chronological Aging in Yeast. In Methods in Enzymology; Academic Press: Cambridge, MA, USA, 2017; Volume 588, pp. 367-394. ISBN 978-0-12-809674-1.

22. Prasad, R.; Kapoor, K. Multidrug Resistance in Yeast Candida. In International Review of Cytology; Academic Press: Cambridge, MA, USA, 2004; Volume 242, pp. 215-248. ISBN 978-0-12-364646-0.

23. Brown, A.J.P.; Brown, G.D.; Netea, M.G.; Gow, N.A.R. Metabolism impacts upon Candida immunogenicity and pathogenicity at multiple levels. Trends Microbiol. 2014, 22, 614-622. [CrossRef] [PubMed]

24. Poljšak, B.; Gazdag, Z.; Pesti, M.; Jenko-Brinovec, Š.; Belagyi, J.; Plesničar, S.; Raspor, P. Pro-oxidative versus antioxidative reactions between Trolox and $\mathrm{Cr}(\mathrm{VI})$ : The role of $\mathrm{H}_{2} \mathrm{O}_{2}$. Environ. Toxicol. Pharmacol. 2006, 22, 15-19. [CrossRef] [PubMed]

25. Stromájer-Rácz, T.; Gazdag, Z.; Belágyi, J.; Vágvölgyi, C.; Zhao, R.Y.; Pesti, M. Oxidative stress induced by HIV-1 F34IVpr in Schizosaccharomyces pombe is one of its multiple functions. Exp. Mol. Pathol. 2010, 88, 38-44. [CrossRef]

26. Tafforeau, L.; Le Blastier, S.; Bamps, S.; Dewez, M.; Vandenhaute, J.; Hermand, D. Repression of ergosterol level during oxidative stress by fission yeast F-box protein Pof14 independently of SCF. EMBO J. 2006, 25, 4547-4556. [CrossRef] [PubMed]

27. Khan, H.; Saeed, M.; Muhammad, N.; Tariq, S.A.; Ghaffar, R.; Gul, F. Antimalarial and free radical scavengering activities of aerial parts of Polygonatum verticillatum (L.) all. and identification of chemical constituents by GC-MS. Pak. J. Bot. 2013, 45, 497-500.

28. Virág, E.; Pesti, M.; Kunsági-Máté, S. Complex formation between primycin and ergosterol: Entropy-driven initiation of modification of the fungal plasma membrane structure. J. Antibiot. 2012, 65, 193-196. [CrossRef] [PubMed]

29. De Cremer, K.; Lanckacker, E.; Cools, T.L.; Bax, M.; De Brucker, K.; Cos, P.; Cammue, B.P.A.; Thevissen, K. Artemisinins, New Miconazole Potentiators Resulting in Increased Activity against Candida albicans Biofilms. Antimicrob. Agents Chemother. 2015, 59, 421-426. [CrossRef] 
30. Li, W.; Mo, W.; Shen, D.; Sun, L.; Wang, J.; Lu, S.; Gitschier, J.M.; Zhou, B. Yeast Model Uncovers Dual Roles of Mitochondria in the Action of Artemisinin. PLoS Genet. 2005, 1, e36. [CrossRef]

31. Romero, D.; Sanabria-Valentín, E.; Vlamakis, H.; Kolter, R. Biofilm Inhibitors that Target Amyloid Proteins. Chem. Biol. 2013, 20, 102-110. [CrossRef]

32. Romero, D.; Aguilar, C.; Losick, R.; Kolter, R. Amyloid fibers provide structural integrity to Bacillus subtilis biofilms. PNAS 2010, 107, 2230-2234. [CrossRef]

33. Rukayadi, Y.; Hwang, J.-K. In Vitro Activity of Xanthorrhizol Isolated from the Rhizome of Javanese Turmeric (Curcuma xanthorrhiza Roxb.) Against Candida albicans Biofilms: Anti-Candida Biofilm Activity of Xanthorrhizol. Phytother. Res. 2013, 27, 1061-1066. [CrossRef] [PubMed]

34. Wu, H.; Moser, C.; Wang, H.-Z.; Høiby, N.; Song, Z.-J. Strategies for combating bacterial biofilm infections. Int. J. Oral Sci. 2015, 7, 1-7. [CrossRef] [PubMed]

35. Girardot, M.; Imbert, C. Natural Sources as Innovative Solutions Against Fungal Biofilms. In Fungal Biofilms and Related Infections: Advances in Microbiology, Infectious Diseases and Public Health Volume 3; Imbert, C., Ed.; Advances in Experimental Medicine and Biology; Springer International Publishing: Cham, Switzerland, 2016; pp. 105-125. ISBN 978-3-319-42360-9.

36. Kerekes, E.-B.; Deák, É.; Takó, M.; Tserennadmid, R.; Petkovits, T.; Vágvölgyi, C.; Krisch, J. Anti-biofilm forming and anti-quorum sensing activity of selected essential oils and their main components on food-related micro-organisms. J. Appl. Microbiol. 2013, 115, 933-942. [CrossRef] [PubMed]

37. Oppenheimer-Shaanan, Y.; Steinberg, N.; Kolodkin-Gal, I. Small molecules are natural triggers for the disassembly of biofilms. Trends Microbiol. 2013, 21, 594-601. [CrossRef] [PubMed]

38. Reen, F.J.; Gutiérrez-Barranquero, J.A.; Parages, M.L.; O'Gara, F. Coumarin: A novel player in microbial quorum sensing and biofilm formation inhibition. Appl. Microbiol. Biotechnol. 2018, 102, 2063-2073. [CrossRef]

39. Sardi, J.D.C.O.; Freires, I.A.; Lazarini, J.G.; Infante, J.; de Alencar, S.M.; Rosalen, P.L. Unexplored endemic fruit species from Brazil: Antibiofilm properties, insights into mode of action, and systemic toxicity of four Eugenia spp. Microb. Pathog. 2017, 105, 280-287. [CrossRef] [PubMed]

40. Verderosa, A.D.; Totsika, M.; Fairfull-Smith, K.E. Bacterial Biofilm Eradication Agents: A Current Review. Front. Chem. 2019, 7, 824. [CrossRef]

41. Sharma, D.; Misba, L.; Khan, A.U. Antibiotics versus biofilm: An emerging battleground in microbial communities. Antimicrob. Resist. Infect. Control 2019, 8, 76. [CrossRef]

42. Tsui, C.; Kong, E.F.; Jabra-Rizk, M.A. Pathogenesis of Candida albicans biofilm. Pathog. Dis. 2016, 74, ftw018. [CrossRef]

43. Papp, G.; Horváth, E.; Mike, N.; Gazdag, Z.; Belágyi, J.; Gyöngyi, Z.; Bánfalvi, G.; Hornok, L.; Pesti, M. Regulation of patulin-induced oxidative stress processes in the fission yeast Schizosaccharomyces pombe. Food Chem. Toxicol. 2012, 50, 3792-3798. [CrossRef]

44. Brown, A.J.P.; Budge, S.; Kaloriti, D.; Tillmann, A.; Jacobsen, M.D.; Yin, Z.; Ene, I.V.; Bohovych, I.; Sandai, D.; Kastora, S.; et al. Stress adaptation in a pathogenic fungus. J. Exp. Biol. 2014, 217, 144-155. [CrossRef] [PubMed]

45. Marcos-Zambrano, L.J.; Escribano, P.; Bouza, E.; Guinea, J. Production of biofilm by Candida and non-Candida spp. isolates causing fungemia: Comparison of biomass production and metabolic activity and development of cut-off points. Int. J. Med. Microbiol. 2014, 304, 1192-1198. [CrossRef] [PubMed]

46. Munusamy, K.; Vadivelu, J.; Tay, S.T. A study on Candida biofilm growth characteristics and its susceptibility to aureobasidin A. Rev. Iberoam. Micol. 2018, 35, 68-72. [CrossRef] [PubMed]

47. Blankenship, J.R.; Mitchell, A.P. How to build a biofilm: A fungal perspective. Curr. Opin. Microbiol. 2006, 9 , 588-594. [CrossRef] [PubMed]

48. Mowat, E.; Lang, S.; Williams, C.; McCulloch, E.; Jones, B.; Ramage, G. Phase-dependent antifungal activity against Aspergillus fumigatus developing multicellular filamentous biofilms. J. Antimicrob. Chemother. 2008, 62, 1281-1284. [CrossRef]

49. Mukherjee, P.K.; Chandra, J.; Kuhn, D.M.; Ghannoum, M.A. Mechanism of fluconazole resistance in Candida albicans biofilms: Phase-specific role of efflux pumps and membrane sterols. Infect. Immun. 2003, 71, 4333-4340. [CrossRef] 
50. Ramage, G.; Rajendran, R.; Sherry, L.; Williams, C. Fungal Biofilm Resistance. Int. J. Microbiol. $2012,528521$. [CrossRef]

51. Stepanović, S.; Vuković, D.; Hola, V.; Di Bonaventura, G.; Djukić, S.; Cirković, I.; Ruzicka, F. Quantification of biofilm in microtiter plates: Overview of testing conditions and practical recommendations for assessment of biofilm production by staphylococci. APMIS 2007, 115, 891-899. [CrossRef]

52. Dowd, S.E.; Sun, Y.; Smith, E.; Kennedy, J.P.; Jones, C.E.; Wolcott, R. Effects of biofilm treatments on the multi-species Lubbock chronic wound biofilm model. J. Wound Care 2009, 18, 508-512. [CrossRef]

53. Peeters, E.; Nelis, H.J.; Coenye, T. Comparison of multiple methods for quantification of microbial biofilms grown in microtiter plates. J. Microbiol. Methods 2008, 72, 157-165. [CrossRef]

54. Alves, F.R.F.; Silva, M.G.; Rôças, I.N.; Siqueira, J.F., Jr. Biofilm biomass disruption by natural substances with potential for endodontic use. Braz. Oral Res. 2013, 27, 20-25. [CrossRef] [PubMed]

55. Kırmusaoğlu, S. The Methods for Detection of Biofilm and Screening Antibiofilm Activity of Agents. In Antimicrobials, Antibiotic Resistance, Antibiofilm Strategies and Activity Methods; Kırmusaoğlu, S., Ed.; IntechOpen: Rijeka, Croatia, 2019; pp. 1-17. ISBN 978-1-78985-789-4.

56. Salari, S.; Sadat Seddighi, N.; Ghasemi Nejad Almani, P. Evaluation of biofilm formation ability in different Candida strains and anti-biofilm effects of Fe $3 \mathrm{O} 4$-NPs compared with Fluconazole: An in vitro study. J. Mycol. Méd. 2018, 28, 23-28. [CrossRef] [PubMed]

57. Alonso, B.; Cruces, R.; Pérez, A.; Sánchez-Carrillo, C.; Guembe, M. Comparison of the XTT and resazurin assays for quantification of the metabolic activity of Staphylococcus aureus biofilm. J. Microbiol. Methods 2017, 139, 135-137. [CrossRef] [PubMed]

58. Azeredo, J.; Azevedo, N.F.; Briandet, R.; Cerca, N.; Coenye, T.; Costa, A.R.; Desvaux, M.; Di Bonaventura, G.; Hébraud, M.; Jaglic, Z.; et al. Critical review on biofilm methods. Crit. Rev. Microbiol. 2017, 43, 313-351. [CrossRef]

59. Kuhn, D.M.; Balkis, M.; Chandra, J.; Mukherjee, P.K.; Ghannoum, M.A. Uses and Limitations of the XTT Assay in Studies of Candida Growth and Metabolism. J. Clin. Microbiol. 2003, 41, 506-508. [CrossRef] [PubMed]

60. Nett, J.E.; Cain, M.T.; Crawford, K.; Andes, D.R. Optimizing a Candida biofilm microtiter plate model for measurement of antifungal susceptibility by tetrazolium salt assay. J. Clin. Microbiol. 2011, 49, 1426-1433. [CrossRef]

61. Gazdag, Z.; Fujs, S.; Kőszegi, B.; Kálmán, N.; Papp, G.; Emri, T.; Belágyi, J.; Pócsi, I.; Raspor, P.; Pesti, M. The abc1 - /coq8 - respiratory-deficient mutant of Schizosaccharomyces pombe suffers from glutathione underproduction and hyperaccumulates $\mathrm{Cd}^{2+}$. Folia Microbiol. 2011, 56, 353-359. [CrossRef]

62. Fujs, Š.; Gazdag, Z.; Poljšak, B.; Stibilj, V.; Milacic, R.; Pesti, M.; Raspor, P.; Batic, M. The oxidative stress response of the yeast Candida intermedia to copper, zinc, and selenium exposure. J. Basic Microbiol. 2005, 45, 125-135. [CrossRef]

63. Das, S.; Gazdag, Z.; Szente, L.; Meggyes, M.; Horváth, G.; Lemli, B.; Kunsági-Máté, S.; Kuzma, M.; Kőszegi, T. Antioxidant and antimicrobial properties of randomly methylated $\beta$ cyclodextrin-Captured essential oils. Food Chem. 2019, 278, 305-313. [CrossRef]

64. Das, S.; Horváth, B.; Šafranko, S.; Jokić, S.; Széchenyi, A.; Kőszegi, T. Antimicrobial Activity of Chamomile Essential Oil: Effect of Different Formulations. Molecules 2019, 24, 4321. [CrossRef]

65. Lee, J.; Dawes, I.W.; Roe, J.-H. Adaptive response of Schizosaccharomyces pombe to hydrogen peroxide and menadione. Microbiology 1995, 141, 3127-3132. [CrossRef] [PubMed]

66. Pesti, M.; Gazdag, Z.; Belágyi, J. In vivo interaction of trivalent chromium with yeast plasma membrane, as revealed by EPR spectroscopy. FEMS Microbiol. Lett. 2000, 182, 375-380. [CrossRef] [PubMed]

67. Rajendran, R.; Sherry, L.; Nile, C.J.; Sherriff, A.; Johnson, E.M.; Hanson, M.F.; Williams, C.; Munro, C.A.; Jones, B.J.; Ramage, G. Biofilm formation is a risk factor for mortality in patients with Candida albicans bloodstream infection-Scotland, 2012-2013. Clin. Microbiol. Infect. 2016, 22, 87-93. [CrossRef] [PubMed]

68. Fai, P.B.; Grant, A. A rapid resazurin bioassay for assessing the toxicity of fungicides. Chemosphere 2009, 74, 1165-1170. [CrossRef] [PubMed] 
69. Van den Driessche, F.; Rigole, P.; Brackman, G.; Coenye, T. Optimization of resazurin-based viability staining for quantification of microbial biofilms. J. Microbiol. Methods 2014, 98, 31-34. [CrossRef] [PubMed]

70. Appiah, T.; Boakye, Y.D.; Agyare, C. Antimicrobial Activities and Time-Kill Kinetics of Extracts of Selected Ghanaian Mushrooms. Evid. Based Complement. Altern. Med. 2017, 2017. [CrossRef]

Sample Availability: Samples of the compounds artemisinin and scopoletin are available from the authors.

(C) 2020 by the authors. Licensee MDPI, Basel, Switzerland. This article is an open access article distributed under the terms and conditions of the Creative Commons Attribution (CC BY) license (http://creativecommons.org/licenses/by/4.0/). 